\title{
Disposição de sedimentos de dragagem em solos tropicais: avaliação da ecotoxicidade com base em bioensaios com alface e de bioacumulação de metais com oligoquetas edáficos
}

\author{
Ricardo Cesar ${ }^{1}$ * \\ Juan Colonese ${ }^{2}$ \\ Edison Bidone $^{1}$ \\ Zuleica Castilhos ${ }^{2}$ \\ Silvia Egler ${ }^{2}$ \\ Helena Polivanov ${ }^{3}$ \\ ${ }^{1}$ Universidade Federal Fluminense (UFF) - \\ Niterói (RJ), Brasil. \\ ${ }^{2}$ Centro de Tecnologia Mineral (CETEM/ \\ $\mathrm{MCTI}$ ) - Rio de Janeiro (RJ), Brasil. \\ ${ }^{3}$ Universidade Federal do Rio de Janeiro \\ (UFRJ) - Rio de Janeiro(RJ), Brasil. \\ *Autor correspondente: \\ geo_ricardocesar@yahoo.com.br
}

\section{Resumo}

O presente trabalho trata da avaliação da ecotoxicidade e da biodisponibilidade de metais associadas à disposição terrestre de sedimentos de dragagem (oriundos da bacia da Baía de Guanabara, RJ) quando misturados a latossolos e chernossolos. Para tanto, bioensaios de germinação com alface (Lactuca sativa) e de bioacumulação de metais com oligoquetas edáficos (Eisenia andrei) foram executados conforme protocolos-padrão (OECD e ISO). Para o ensaio de germinação, o gradiente de dose de sedimento aplicado ao solo variou de 0 (solo puro) a $33 \%$. Para o ensaio de bioacumulação, empregou-se a dose de $6,66 \%$, com base em trabalhos prévios. A dose de sedimento capaz de inibir a germinação de $50 \%$ das sementes (CE50) foi estimada por meio da análise de PriProbit. Os resultados revelaram níveis maiores de ecotoxicidade para as misturas de latossolo (CE50=3,58\%) em detrimento às de chernossolo (CE50=4,19\%). A abundância de argilominerais expansivos e a alta fertilidade natural dos chernossolos podem ter contribuído para reduzir a ecotoxicidade desses tratamentos. O ensaio de bioacumulação com E. andrei revelou um balanço de massa positivo do mercúrio em tecidos de oligoquetas, sugerindo a ocorrência potencial de efeitos nocivos à saúde dos animais expostos. As concentrações de chumbo, cromo e níquel em tecidos de oligoquetas ficaram abaixo do limite de detecção, indicando baixa biodisponibilidade. As concentrações de zinco e cobre foram as maiores dentre os metais estudados, fato que pode estar atrelado ao papel essencial que esses metais desempenham no metabolismo desses animais.

Palavras-chave: sedimentos dragados, solos, alface, oligoquetas, bioensaios.

\section{Abstract}

This study consists of the ecotoxicity assessment associated with the terrestrial disposal of dredged sediments (from the Guanabara Bay basin, RJ) when mixed with ferralsols and chernosols. Germination bioassays with lettuce (Lactuca sativa) and bioaccumulation assays with earthwor$m s$ (Eisenia andrei) were performed according to standard protocols (OECD and ISO). Doses gradients used in the germination assays varied between 0 (pure soil) and 33\%. The dose of sediment applied onto soil in the bioaccumulation assay was 6,66\%, in agreement with previous works. The dose of sediment required to inhibit the germination of $50 \%$ of the exposed (EC50) seeds was estimated by using PriProbit analysis. 
The results revealed higher levels of ecotoxicity for the ferralsol mixtures $(E C 50=3.58 \%)$ rather than chernosols treatments (EC50 $=4.19 \%)$. The abundance of expansive clay minerals and higher fertility levels in chernosols may have reduced the ecotoxicity of such treatments. The bioaccumulation assay with E. andrei revealed a positive balance of mercury in earthworm tissues, suggesting potential occurrences of damages on the health of those animals. The concentrations of lead, chromium and nickel were bellow the detection limits. The concentrations of zinc and copper were the highest ones among the studied metals, fact that may be associated with the essential role played by such metals in the earthworm metabolism. Keywords: dredged sediments, soils, lettuce, earthworms, bioassays.

\section{INTRODUÇÃO}

Rejeitos industriais e domésticos têm sido, durante décadas, descartados de maneira inapropriada em sistemas costeiros do Estado do Rio de Janeiro (RJ), sobretudo na bacia da Baía de Guanabara (Silva et al. 2007, Silveira et al. 2010, Machado et al. 2011). A dragagem desses sistemas aquáticos é frequentemente requerida com o objetivo de restaurar a navegabilidade de corpos hídricos assoreados, bem como de prevenir e/ou atenuar os impactos oriundos da eutrofização, da proliferação de patógenos e da contaminação por metais e compostos orgânicos (Ho et al. 2002, Munns et al. 2002, Machado et al. 2011). Nesse contexto, a disposição sustentável dos sedimentos de dragagem (via de regra, na ordem de milhões de $\mathrm{m}^{3}$ ) torna-se temática de extrema relevância e alguns autores descrevem o reaproveitamento desses materiais na construção civil, no engordamento de praias e como insumo na agricultura (Ho et al. 2002, Munns et al. 2002, Vacha et al. 2011).

No Brasil, a disposição terrestre (i.e., em solos) de sedimentos dragados é regulamentada pela Resolução n ${ }^{\circ} 454$ do CONAMA (2012). Essa Resolução está fundamentada em padrões estabelecidos para ecossistemas oriundos de clima temperado e, por conseguinte, carece de fundamentos pedogeoquímicos e ecotoxicológicos que justifiquem sua aplicação em regiões tropicais (Cesar et al. 2013a). Além disso, a referida resolução não está calcada na realização de bioensaios com organismos de solo, fato ainda que limita a avaliação dos efeitos deletérios à saúde do ecossistema do solo. Nesse aspecto, é importante ressaltar que as propriedades do substrato pedológico $(\mathrm{pH}$, condutividade elétrica, textura,

\section{MATERIAIS E MÉTODOS}

\subsection{Amostragem e preparação dos materiais}

A amostra de sedimento dragado foi obtida no Canal do Cunha (bacia da Baía de Guanabara, RJ), em três distintos pontos de coleta (Figura 1), a fim de gerar uma única amostra composta. Tal escolha foi feita porque a Baía de Guanabara sofre há décadas com o descarte indiscriminado de rejeitos industriais e esgoto doméstico, sendo a contaminação por metais e hidrocarbonetos de petróleo amplamente reportada na literatura (Silva et al.2007, Silveira et al. 2010, Machado argilominerais, oxi-hidróxidos de ferro e alumínio, entre outros) desempenham papel de suma relevância na mobilidade, biodisponibilidade e ecotoxicidade de metais (Natal-da-Luz et al. 2008, Chelinho et al. 2011, Cesar et al. 2013a). Assim, uma abordagem geoquímica dos solos, integrada à análise ecotoxicológica, torna-se fundamental ao estabelecimento de indicadores de sustentabilidade capazes de refletir as especificidades das principais ocorrências pedológicas, subsidiando a tomada de decisão em medidas de controle da poluição e de preservação da biodiversidade do solo.

Os oligoquetas edáficos (Eisenia andrei, Eisenia foetida) são amplamente utilizados em bioensaios com solos contaminados (Nahmani et al. 2007, Natal-da-Luz et al. 2009, Van Gestel et al. 2011, Cesar et al. 2012). As razões que justificam o emprego desses animais residem no seu cultivo simples em laboratório, na relativa sensibilidade à presença de agentes tóxicos e no curto ciclo de vida, além de eles serem um elo importante da cadeia trófica terrestre (servindo de alimento para outros organismos) (Hinton \& Veiga 2002). A alface da espécie Lactuca sativa é também frequentemente utilizada em bioensaios sobretudo por necessitar de um período curto para germinação e por ter implicações na ocorrência potencial de efeitos adversos à saúde humana por ingestão de alimentos contaminados.

O presente trabalho trata da avaliação da ecotoxicidade potencial e da biodisponibilidade de metais em latossolos e chernossolos tratados com sedimentos de dragagem (contendo esgoto doméstico e metais), utilizando ensaios agudos de germinação com $L$. sativa e de bioacumulação de metais com E. andrei. et al. 2011). A amostra foi coletada com o auxílio de uma draga inox do tipo Van Veen. Após ter sido seca à temperatura ambiente, a amostra foi quarteada e, posteriormente, moída em moinho de barra. O procedimento de moagem da amostra se deve à simulação do pior cenário de risco ecológico, tendo em vista que a redução da granulometria resulta em maior superfície específica de contato, tendendo a aumentar a biodisponibilidade dos contaminantes. 
Figura 1

Localização dos pontos de coleta de sedimento ao longo do Canal do Cunha

(bacia da Baía de Guanabara, RJ).

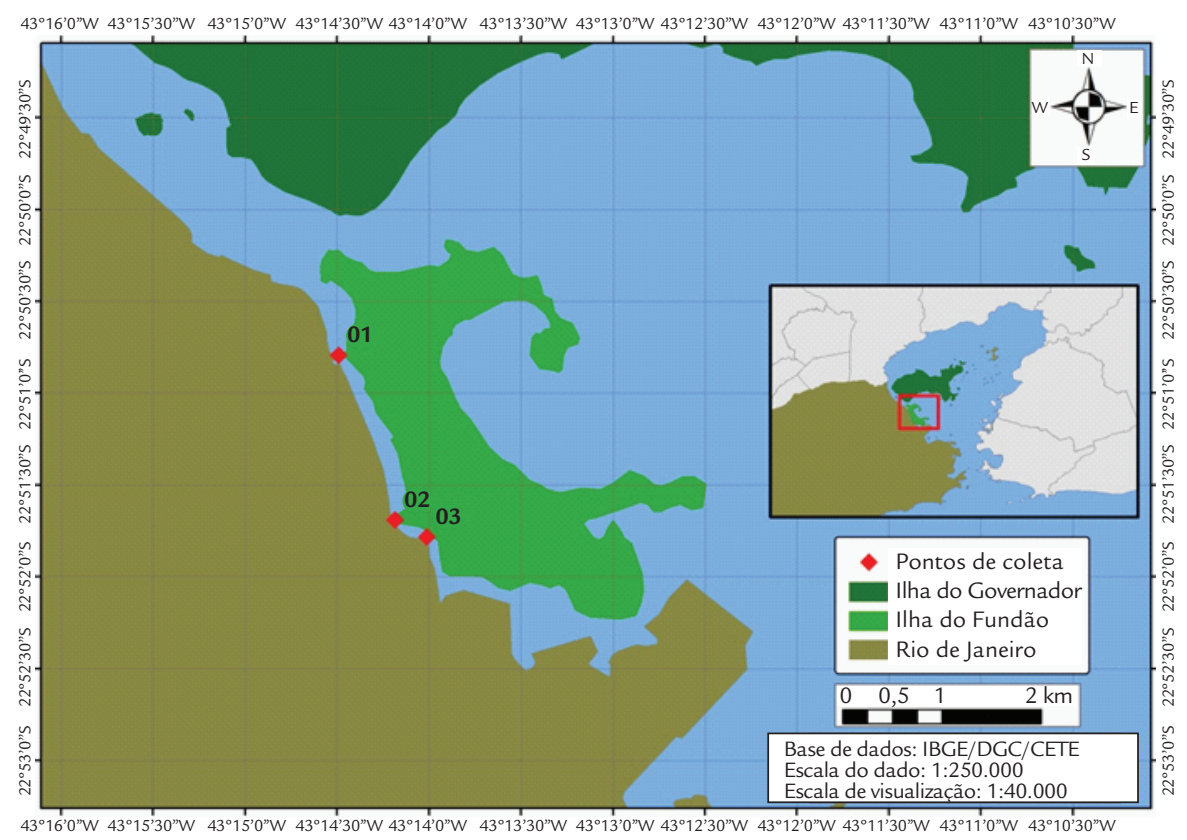

As amostras de latossolo e de chernossolo (horizonte B) foram obtidas nos municípios de Duque de Caxias (RJ $22^{\circ} 41^{\prime} 34.2^{\prime \prime S}, 43^{\circ} 17^{\prime} 14.5^{\prime \prime} \mathrm{W}$ ) e Rio de Janeiro (RJ $22^{\circ}$ $51^{\prime} 22,5$ "S, $43^{\circ} 30^{\prime}$ 0,7”W), respectivamente. Após secagem à temperatura ambiente, as amostras foram desagregadas, peneiradas a $2 \mathrm{~mm}$ e quarteadas. A escolha pelo horizonte $\mathrm{B}$ se deve ao fato de que ele guarda as características físicas, químicas e mineralógicas dos solos e, dessa forma, possibilita a avaliação da influência das propriedades dos solos sobre a ecotoxicidade. Além disso, a simulação da disposição do sedimento sobre o horizonte B permite a avaliação do potencial de aplicação de materiais dragados como regeneradores de áreas degradadas em que o horizonte A tenha sido removido.

\subsubsection{Características físicas, mineralógicas e geoquímicas das amostras usadas em bioensaios}

Cesar et al. (2012, 2013a) indicaram alguns aspectos da composição física, química e mineralógica das amostras de solo utilizadas neste trabalho (Tabela 1 ). O chernossolo apresenta abundância de argilominerais expansivos [ilita $(2 \%)$, interestratificado ilita-esmectita $(4 \%)$ e vermiculita $(73 \%)]$ em sua fração argila, baixa permeabilidade, alta capacidade de troca catiônica (CTC), elevados teores de $\mathrm{Mg}^{+2}, \mathrm{Ca}^{+2}, \mathrm{~K}^{+}$(alta fertilidade natural), $\mathrm{pH}$ em torno 6,2 e teor de caulinita ao redor de $21 \%$. O latossolo consiste de um material mais ácido ( $\mathrm{pH}=4,2)$, contém altas concentrações de ferro total, além da presença de goethita ( $8 \%$ ) e gibbsita (13\%), é mais permeável, é de mineralogia essencialmente caulinítica (79\%), apresenta teores baixos de nutrientes (baixa fertilidade natural) e altas concentrações de alumínio.

A concentração total de metais na amostra do sedimento dragado está descrita em Cesar et al. (2013a). Em termos de toxicidade, o $\mathrm{Hg}$ aparece como o metal mais crítico, visto que sua concentração excede o Nível 2 estabelecido por CONAMA (2012). Com exceção do Ni, todos os metais estudados apresentaram concentrações acima do Nível 1. De acordo com Cesar et al. (2013a), nesse sedimento ocorre a predominância da fração da argila (53,2\%). A mineralogia da amostra total revelou a ocorrência de quartzo, caulinita, gibbsita e muscovita (Cesar et al., 2013a).
Tabela 1

Aspectos físicos e químicos das amostras de solo e de sedimento de dragagem utilizadas em bioensaios.

\begin{tabular}{|c|c|c|c|c|}
\hline Parâmetros do solo & & Latossolo & Chernossolo & Sedimento dragado \\
\hline \multirow{3}{*}{$\begin{array}{l}\text { Textura } \\
(\%, n=3)\end{array}$} & Argila & 58 & 24 & 53,2 \\
\hline & Silte & 6 & 35 & 27,4 \\
\hline & Areia & 36 & 41 & 19,4 \\
\hline \multirow{2}{*}{$\mathrm{pH}(\mathrm{n}=3)$} & $\mathrm{H}_{2} \mathrm{O}$ & 4,2 & 6,2 & 8,2 \\
\hline & $\mathrm{KCl}$ & 3,6 & 4,1 & - \\
\hline \multirow{4}{*}{$\begin{array}{l}\text { Complexo sortivo } \\
\left(\mathrm{cmol}_{\mathrm{c}} / \mathrm{dm}^{3}, \mathrm{n}=3\right)\end{array}$} & $\mathrm{Mg}^{+2}+\mathrm{Ca}^{+2}$ & 0,2 & 40,5 & - \\
\hline & $\mathrm{K}^{+}$ & 0,02 & 0,03 & - \\
\hline & $\mathrm{Na}^{+}$ & 0,03 & 1,44 & - \\
\hline & CTC & 2,3 & 48,3 & - \\
\hline \multirow{2}{*}{$\begin{array}{l}\text { Concentrações totais } \\
(\%, n=3)\end{array}$} & $\mathrm{Al}$ & 26,4 & 18,9 & 4,5 \\
\hline & $\mathrm{Fe}$ & 11,3 & 7,9 & 4 \\
\hline $\begin{array}{l}\text { Matéria orgânica } \\
(\%, n=3)\end{array}$ & - & 0,22 & 0,34 & 19 \\
\hline
\end{tabular}

Fonte: Adaptado de Cesar et al. (2013a).

CTC: capacidade de troca catiônica. 


\subsubsection{Preparação das misturas solo:sedimento}

A simulação da disposição terrestre do sedimento dragado foi realizada por meio da preparação de misturas de diferentes proporções solo:sedimento. A definição dessas proporções está baseada em Cesar et al. (2013a). Os referidos autores executaram bioensaios agudos (14 dias) com Eisenia andrei utilizando essas mesmas amostras de solos e sedimento, e empregaram as seguintes proporções de mistura (isto é, doses de sedimento dragado aplicadas aos solos): 6,$66 ; 13,32 ; 19,98 ; 26,64$; $33,3 \%$ - para o latossolo; 6,$58 ; 13,16 ; 19,74 ; 26,32$; $32,90 \%$ - para o chernossolo. Assim, para realização

\subsection{Determinação de metais nos oligoquetas}

A determinação dos teores totais de zinco $(\mathrm{Zn})$, cobre $(\mathrm{Cu})$, níquel $(\mathrm{Ni})$, chumbo $(\mathrm{Pb})$, cromo $(\mathrm{Cr})$ e mercúrio $(\mathrm{Hg})$ na amostra de sedimento in natura e nas proporções de mistura solo:sedimento (ver item 2.1) foi obtida em Cesar et al. (2013a), que estudaram a ecotoxicidade aguda (para E. andrei) associada à disposição desse mesmo do ensaio com $L$. sativa, foram utilizadas essas mesmas proporções, com réplicas adicionais de 3,33 e 3,29\% em latossolo e chernossolo, respectivamente.

A escolha da proporção solo:sedimento para o ensaio de bioacumulação de metais com E. andrei foi também baseada nos resultados de mortalidade obtidos por Cesar et al. (2013a), com o emprego de bioensaios agudos. Optou-se por trabalhar com uma dose de sedimento que não fosse capaz de provocar a morte significativa de animais, sob uma exposição aguda. Dessa forma, utilizou-se a dose de $6,66 \%$ (Cesar et al., 2013a).

sedimento quando misturado a essas mesmas amostras de solo. As concentrações de $\mathrm{Hg}, \mathrm{Cu}, \mathrm{Zn}, \mathrm{Pb}, \mathrm{Ni}$ e $\mathrm{Cr}$ nas misturas de solo:sedimento estão descritas na Tabela 2 . Para maiores detalhes, consulte Cesar et al. (2013a). As concentrações de metais no sedimento dragado in natura estão apresentadas na Tabela 3.

\begin{tabular}{lcc}
\hline Elemento & Latossolo:sedimento $\mathbf{( m g / k g )}$ & Chernossolo:sedimento $\mathbf{( m g / k g )}$ \\
\hline $\mathrm{Hg}$ & $0,010-0,300$ & $0,032-0,307$ \\
\hline $\mathrm{Cu}$ & $150-410$ & $15,8-35,9$ \\
\hline $\mathrm{Zn}$ & $34-270$ & $40-116$ \\
\hline $\mathrm{Pb}$ & $46-218$ & $5,2-36,5$ \\
\hline $\mathrm{Ni}$ & $20,9-51,6$ & $1,60-6,52$ \\
\hline $\mathrm{Cr}$ & $81-370$ & $3,1-27,2$ \\
\hline
\end{tabular}

Tabela 2

Faixas de concentrações de metais pesados em misturas solo:sedimento utilizadas em bioensaios.

Fonte: Adaptado de Cesar et al. (2013a).

\begin{tabular}{lccccccc}
\hline \multirow{2}{*}{ Localidade dragada } & \multicolumn{5}{c}{ Metais $\mathbf{( m g / k g )}$} & \multirow{2}{*}{ Autores } \\
\cline { 2 - 6 } & $\mathbf{Z n}$ & $\mathbf{C u}$ & $\mathbf{P b}$ & $\mathbf{C r}$ & $\mathbf{N i}$ & $\mathbf{H g}$ & Cesar et al. (2013b) \\
\hline Rios diversos da Baixada Fluminense (RJ) & 114 & 26,3 & 19 & 93,8 & 8,6 & 0,16 & Hortellani et al. (2005) \\
\hline Estuário Santos-São Vicente (SP) & 312 & - & 89,9 & 97,5 & 44,2 & 0,75 & Ho et al. (2002) \\
\hline Porto de Nova York (EUA) & 324 & 200 & 186 & - & 141 & - & Vacha et al. (2011) \\
\hline Rios diversos da República Tcheca & 308,3 & 65,6 & 57,2 & 131 & 46,8 & 0,27 & Cesar et al. (2013a) \\
\hline Canal do Cunha (bacia da Baía de Guanabara, RJ) & 329 & 92 & 124 & 94,5 & 20,3 & 1,08 & Resolução 454 (CONAMA 2012) \\
\hline Nível 1** & 150 & 34 & 46,7 & 81 & 20,9 & 0,3 & \\
\hline Nível 2*** & 410 & 270 & 218 & 370 & 51,6 & 1 & \\
\hline
\end{tabular}

*Amostra usada nos ensaios do presente artigo; **limiar de baixa probabilidade de efeitos adversos à biota; ***limiar de alta probabilidade de efeitos adversos à biota.

A determinação das concentrações totais de $\mathrm{Zn}, \mathrm{Cu}$, $\mathrm{Ni}, \mathrm{Pb}$ e $\mathrm{Cr}$ nos oligoquetas do ensaio de bioacumulação envolveu a solubilização de $1 \mathrm{~g}$ de amostra em uma mistura ácida composta de $\mathrm{HF}: \mathrm{HCl}: \mathrm{HClO}_{4}$, na proporção de 2:1:1, em béquer de platina. Após a secura da solução em chapa a $120^{\circ} \mathrm{C}$, ela foi retomada com ácido nítrico $5 \%\left(\mathrm{HNO}_{3}\right)$ para medição em espectrômetro de absorção atômica (Varian,
Tabela 3

Determinação da concentração total de metais na amostra de sedimento dragado estudada (Cesar et al. 2013a) e comparação com teores obtidos em diferentes localidades dragadas.

Spectra 55b). Para a determinação do Hg total, utilizou-se um analisador de mercúrio da marca LUMEX modelo RA 915+ acoplado a um acessório de pirólise (para a queima da amostra, geração de vapor de $\mathrm{Hg}$, e sua quantificação). Previamente à análise química, as amostras biológicas (oligoquetas) foram submetidas a congelamento, liofilização, trituração e homogeneização. 


\subsection{Ensaio de germinação com Lactuca sativa}

As sementes de L. sativa utilizadas neste trabalho foram obtidas sem o emprego de agrotóxicos. O ensaio foi conduzido com 5 réplicas e em pratos plásticos redondos $(12 \mathrm{~cm}$ de diâmetro e $2 \mathrm{~cm}$ de profundidade), preenchidos com $100 \mathrm{~g}$ de solo-teste (mistura solo:sedimento) ajustada para $40-60 \%$ da capacidade máxima de retenção de água $(\mathrm{OECD}, 1984)$. Em cada réplica foram adicionadas 40 sementes. Aproximadamente $100 \mathrm{~g}$ de areia fina, constituída basicamente de quartzo (obtida com o Instituto de Pesquisas Tecnológicas, conforme escala de Wentworth, ou seja, de 0,125 a $0,250 \mathrm{~mm}$ ), foram adicionadas a cada réplica com o objetivo de reduzir a perda de umidade para a atmosfera e de aumentar a agregabilidade do solo (OECD, 1984).
O ensaio teve duração de 5 dias, sob temperatura controlada $\left(22 \pm 2^{\circ} \mathrm{C}\right)$ e foto-período de $16: 8 \mathrm{~h}$ (luz:escuridão). Ao final do ensaio, o número de sementes germinadas foi contabilizado. A dose de sedimento dragado capaz de inibir a germinação de $50 \%$ das sementes expostas (CE50; expressa em porcentagem de sedimento adicionada ao solo) foi estimada com o emprego da análise de PriProbit (Sakuma, 1998). A significância das diferenças entre o número de sementes germinadas nas misturas-teste e na amostra controle (solo sem adição de sedimento; doses $0 \%$ ) foi verificada com a análise de Kruskall-Wallis, utilizando o software STATISTICA para Windows.

\subsection{Ensaio de bioacumulação de metais com Eisenia andrei}

O procedimento adotado para este ensaio baseou-se nas recomendações de ASTM (2004). O ensaio foi somente realizado com o latossolo em razão da indisponibilidade de material e de oligoquetas aptas para a execução do ensaio com chernossolo. O ensaio é realizado com 90 oligoquetas adultos com peso semelhante (entre 250 e $700 \mathrm{mg}$ ) por réplica $(\mathrm{n}=3$; ao todo 270 indivíduos), sob iluminação constante, temperatura de $22 \pm 2^{\circ} \mathrm{C}$ e umidade do solo ajustada para $40-60 \%$ da capacidade máxima de retenção de água. O ensaio é dividido em duas etapas: bioacumulação e depuração. Durante a etapa de biocumulação, os oligoquetas são expostos ao solo contaminado (nesse caso, tratado com $6,66 \%$ de sedimento). Em dias previamente estabelecidos $\left(4^{\circ}, 7^{\circ}, 14^{\circ}, 21^{\circ}, 28^{\circ}\right.$ dia), 10 indivíduos são retirados de cada réplica e deixados sobre papel absorvente contendo água destilada, por 24 horas, para o esvaziamento do conteúdo intestinal. Após essa etapa, os animais são eutanasiados, conge-

\section{RESULTADOS E DISCUSSÃO}

\subsection{Metais no sedimento dragado}

A Tabela 3 apresenta uma comparação dos valores de metais na amostra do sedimento dragado estudado com outras localidades dragadas ou que deverão sofrer processos de dragagem. Nesse aspecto, a concentração obtida para o $\mathrm{Hg}$ $(1,08 \mathrm{mg} / \mathrm{kg})$ pode ser, de fato, considerada alta, uma vez que o teor está quase uma ordem de grandeza acima dos sedimentos dragados da baixada fluminense e, além disso, chega a exceder a concentração do Estuário Santos-Cubatão, uma área que sofreu com o despejo de efluentes da indústria cloro-soda. No que se refere ao Zn, este é um bom indicador de contaminação por

\subsection{Ensaio de germinação com Lactuca sativa}

A determinação dos valores de CE50 de germinação revelou níveis maiores de ecotoxicidade para os tratamentos de latossolo (CE50 $=3,58 \%$ ) em comparação às misturas de chernossolo (CE50=4,19\%) (Figura 1). Não foi possível lados e enviados para a determinação de metais nos tecidos. A avaliação da biodisponibilidade de metais foi realizada por meio do cálculo do fator de bioconcentração (FBC), uma razão entre a concentração total do metal no organismo pela concentração no solo (Liu et al. 2005). Quando a concentração do metal encontrava-se abaixo do limite de detecção, utilizou-se o valor do próprio limite para a estimativa do FBC.

Ao final da etapa de bioacumulação, os organismos remanescentes são transferidos para um solo artificial não contaminado, de forma a verificar o potencial de excreção de metais pelo metabolismo (fase de depuração). O solo artificial foi composto de $70 \%$ de areia, $20 \%$ de caulim e $10 \%$ de pó de casca de coco, de acordo com as recomendações de Garcia (1996). Análogo à fase de depuração, 10 indivíduos foram retirados em dias previamente definidos $\left(4^{\circ}, 7^{\circ}, 14^{\circ}, 21^{\circ}, 28^{\circ}\right.$ dia $)$ e enviados para a análise química de metais em seus tecidos. esgoto doméstico. Nesse contexto, a concentração obtida para o $\mathrm{Zn}(320 \mathrm{mg} / \mathrm{kg})$ foi capaz de exceder o teor determinado para as demais localidades investigadas (incluindo áreas altamente impactadas por esgoto, como a Baixada Fluminense, estuário Santos-São Vicente e o porto de Nova York), indicando uma contribuição expressiva do esgoto doméstico na contaminação. As concentrações de $\mathrm{Cr}(94,5 \mathrm{mg} / \mathrm{kg})$ e $\mathrm{Pb}(124 \mathrm{mg} / \mathrm{kg})$, metais de reconhecida toxicidade, também foram elevadas, e somente o teor de $\mathrm{Pb}$ quantificado para o Porto de Nova York (186 mg/kg) excedeu o valor determinado para o Canal do Cunha. estimar intervalos de $95 \%$ de confiança para os valores de CE50 determinados. Relações dose-resposta positivas e significativas foram constatadas entre o incremento de dose de sedimento no solo e a redução do número de sementes 
germinadas em misturas de ambas as classes de solo (Pearson, $\left.\mathrm{p}<0,05 ; \mathrm{r}^{2}>0,5\right)$. Todas as doses de sedimento foram também capazes de reduzir os níveis de germinação, em ambos os solos (Figura 2).

Tais resultados apontam para a influência potencial das propriedades dos solos estudados na ecotoxicidade observada, sendo um maior potencial tóxico atribuído às misturas de latossolo (menor valor de CE50). Uma vez que ambas as classes de solo apresentam conteúdos similares de matéria orgânica — visto que foram coletadas no horizonte B (Cesar et al. 2013a) —, é muito provável que tal parâmetro não tenha tido influência preponderante na diferença entre os efeitos observados para os tipos de solos estudados. O mesmo raciocínio se aplica ao $\mathrm{pH}$, cujos valores foram similares em ambas as misturas de latossolo:sedimento e chernossolo:sedimento (variando entre 5 e 7 unidades, aproximadamente). Por outro lado, diferenças em termos de mineralogia das argilas e de fertilidade podem ter sido atributos importantes de redução da toxicidade.

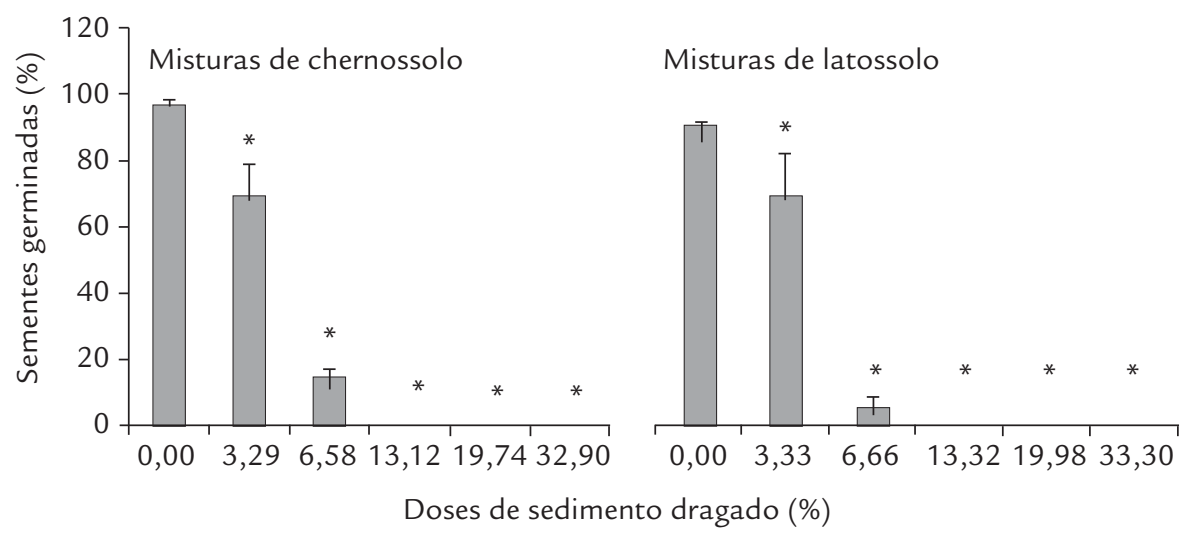

*Germinação significativamente diferente do controle (Kruskall-Wallis; $p<0,05$ ).
Figura 2

Germinação de sementes de Lactuca sativa quando expostas a latossolos e chernossolos tratados com distintas de doses de sedimento dragado.
A literatura aponta que a presença diferenciada de argilominerais expansivos pode alterar a ecotoxicidade e a mobilidade geoquímica de metais para a solução do solo (Matzke et al. 2008, Cesar et al. 2010a, 2010b, 2012, 2013a) em razão de sua elevada CTC e sua alta capacidade de promover o sequestro geoquímico de contaminantes catiônicos. Nesse contexto, Cesar et al. (2012), ao estudarem a ecotoxicidade de latossolos e chernossolos tratados com lodo de esgoto doméstico utilizando bioensaios agudos com E. andrei, relataram uma redução significativa dos efeitos letais para as misturas de chernossolos, em que se verifica a abundância de argilominerais expansivos. Cesar et al. (2013a), ao avaliarem a ecotoxicidade aguda dessa mesma amostra de sedimento em latossolos e chernossolos, também constataram a diminuição significativa da mortalidade de $E$. andrei em misturas de Chernossolo. Matske et al. (2008)

\subsubsection{Ensaio de bioacumulação de metais com Eiseniaandrei}

Os resultados referentes às concentrações totais de metais em tecidos de oligoquetas e seus respectivos valores de FBC estão demonstrados na Tabela 4. Para o cálculo do FBC, as concentrações de $\mathrm{Hg}, \mathrm{Cu}, \mathrm{Zn}, \mathrm{Pb}, \mathrm{Ni}$ e $\mathrm{Cr}$ na mistura latossolo:sedimento (dose de 6,66\%) foram compiladas de Cesar et al. (2013a) e correspondem a 0,162; 12,5; 67,3; 20,4; 4,06; e 13,1 mg/kg, respectivamente.

Os valores de FBC para $\mathrm{Hg}$ foram baixos $(<0,5)$ e apontam para uma baixa biodisponibilidade do metal, a exemplo do observado para o bioensaio agudo (14 dias) com E. andrei executado por Cesar et al. (2013a) em la- também indicaram a redução significativa da toxicidade de substâncias orgânicas para duas espécies de vegetais (Triticuma estivum e Lepidium sativum) em solos contendo argilominerais 2:1 (vermiculita).

No que se refere aos tratamentos sem adição de sedimento (doses $0,00 \%$ ), foi possível observar níveis maiores de germinação para o chernossolo. Cesar et al. (2013c) também reportaram fenômeno semelhante para reprodução de colêmbolos (Folsomia candida) e de enquitreídeos (Enchytraeuds crypticus) ao avaliarem a ecotoxicidade crônica dessa mesma amostra de sedimento dragado em latossolos e chernossolos. Nesse aspecto, a abundância de nutrientes (alta fertilidade natural) em chernossolo pode ter favorecido a germinação das sementes (independentemente da adição de sedimento), em detrimento ao latossolo, onde a disponibilidade geoquímica de nutrientes é muito baixa comparada àquela encontrada em chernossolo (ver item 2.1.).

tossolo tratado com essa mesma amostra de sedimento. A incorporação do $\mathrm{Hg}$ parece ser mais efetiva nos primeiros sete dias de exposição em solo contaminado. Os oligoquetas não foram capazes de depurar (eliminar) a quantidade de $\mathrm{Hg}$ estocada na etapa de bioacumulação (balanço de massa positivo: [Hg estocado $]>[\mathrm{Hg}$ eliminado]). Tal fenômeno também foi observado por Cesar et al. (2010a) em experimentos de bioacumulação utilizando latossolo acrescido de lodo de esgoto doméstico. Além disso, ao serem executados ensaios de bioacumulação com E. andrei em latossolos artificialmente contaminados por $\mathrm{Hg}^{+2}$, Cesar et al. (2010b) 


\begin{tabular}{|c|c|c|c|c|c|c|c|c|c|c|c|c|}
\hline \multirow{2}{*}{ Dias de exposição } & \multicolumn{2}{|c|}{$\mathrm{Cu}$} & \multicolumn{2}{|c|}{ Zn } & \multicolumn{2}{|c|}{$\mathrm{Pb}$} & \multicolumn{2}{|c|}{$\mathrm{Cr}$} & \multicolumn{2}{|c|}{$\mathrm{Hg}$} & \multicolumn{2}{|c|}{$\mathrm{Ni}$} \\
\hline & $\mathrm{OL}$ & FBC & $\mathrm{OL}$ & FBC & $\mathrm{OL}$ & FBC & OL & FBC & OL & FBC & $\mathrm{OL}$ & FBC \\
\hline 0 & 12,00 & - & 77,7 & - & 2,2 & - & $<0,2$ & - & 0,024 & - & $<0,2$ & - \\
\hline $4^{*}$ & 14,18 & 0,96 & 84,34 & 1,25 & $<1,4$ & 0,1 & $<0,2$ & 0,0 & 0,037 & 0,2 & $<0,2$ & 0,0 \\
\hline $7^{*}$ & 14,31 & 1,14 & 85,56 & 1,27 & $<1,4$ & 0,1 & $<0,2$ & 0,0 & 0,042 & 0,3 & $<0,2$ & 0,0 \\
\hline $14^{*}$ & 15,27 & 1,15 & 88,78 & 1,32 & $<1,4$ & 0,1 & $<0,2$ & 0,0 & 0,044 & 0,3 & $<0,2$ & 0,0 \\
\hline $21^{*}$ & 15,51 & 1,22 & 90,43 & 1,34 & $<1,4$ & 0,1 & 0,32 & 0,0 & 0,044 & 0,3 & 0,27 & 0,0 \\
\hline $14^{* *}$ & 13,65 & - & 81,29 & - & $<1,4$ & - & $<0,2$ & - & 0,040 & - & $<0,2$ & - \\
\hline $21^{* *}$ & 13,01 & - & 80,77 & - & $<1,4$ & - & $<0,2$ & - & 0,037 & - & $<0,2$ & - \\
\hline $28^{* *}$ & 12,59 & - & 78,02 & - & $<1,4$ & - & $<0,2$ & - & 0,032 & - & $<0,2$ & - \\
\hline
\end{tabular}

Tabela 4

Concentrações totais $(\mathrm{mg} / \mathrm{kg})$ e correspondente fator de bioconcentração de metais pesados em tecidos de oligoquetas expostos a latossolo tratado com $6,66 \%$ de sedimento dragado: 28 dias de exposição em solo-teste (fase de bioacumulação) e solo artificial (fase de depuração/excreção).
*Etapa de bioacumulação; **etapa de depuração; OL: tecido de oligoquetas; FBC: fator de bioconcentração. mostraram que os oligoquetas foram capazes de eliminar apenas cerca de 1/4 do total bioacumulado.

Por causa de sua elevada e reconhecida toxicidade (WHO, 1990), o balanço de massa positivo de Hg em oligoquetas merece maior atenção no que diz respeito à saúde dos animais expostos. Com relação a isso, Veiga e Hinton (2001) reportam a existência de fenômenos de metilação de formas inorgânicas de Hg no trato intestinal dos oligoquetas, via ação de bactérias redutoras de sulfato - fato que supostamente poderia dificultar sua eliminação pelo metabolismo. De fato, Cesar et al. (2008), ao quantificarem as concentrações de metilmercúrio $(\mathrm{MeHg})$ em tecidos de oligoquetas (Eisenia andrei) expostas a solos degradados pela garimpagem de ouro, verificaram que cerca de $20 \%$ do $\mathrm{Hg}$ total correspondia a MeHg. Contudo, mais estudos ainda são necessários para detalhar e/ou validar a ocorrência potencial de fenômenos de biotransformação interna de $\mathrm{Hg}$ no intestino dos oligoquetas.

A determinação dos teores de $\mathrm{Pb}, \mathrm{Cr}$ e $\mathrm{Ni}$ em tecidos de oligoquetas revelou valores abaixo dos limites de detecção do método analítico empregado, indicando baixa biodisponibilidade para os oligoquetas (Tabela 2). Os valores de

\section{CONCLUSÕES}

As propriedades dos solos estudados desempenharam papel crucial na toxicidade observada para $L$. sativa. A abundância de argilominerais expansivos e a alta fertilidade dos chernossolos parecem exercer papel importante na redução da ecotoxicidade. O ensaio de bioacumulação de metais revelou que os oligoquetas não foram capazes de eliminar todo o estoque de $\mathrm{Hg}$ bioacumulado, indicando a necessidade de estudos de maior detalhamento no que se refere à saúde e fisiologia dos animais expostos. Além disso, os oligoquetas foram capazes de acumular altas concentrações de $\mathrm{Zn}$ e $\mathrm{Cu}$
FBC de $\mathrm{Zn}$ e $\mathrm{Cu}$, por outro lado, foram os maiores entre os metais estudados - maior do que 1 , indicando que houve bioacumulação (Liu et al. 2005). O Zn e o Cu são metais reconhecidamente tóxicos para os oligoquetas edáficos (Lukkari et al. 2005). Por outro lado, é importante notar que, em baixas concentrações, estes são elementos essenciais ao seu metabolismo e fisiologia. O Zn desempenha papel vital no desenvolvimento, crescimento e regeneração dos tecidos dos oligoquetas, enquanto o $\mathrm{Cu}$ participa no transporte de substâncias entre as células e os tecidos (Lukkari et al. 2005). Efeitos adversos associados à exposição ao $\mathrm{Zn}$ e $\mathrm{Cu}$ estão usualmente atrelados ao excesso desses elementos no solo.

Ainda no que se refere ao $\mathrm{Zn}$ e $\mathrm{Cu}$, foi possível observar um aumento do FBC ao longo da etapa de bioacumulação (Tabela 2). Por outro lado, a incorporação e eliminação de ambos os metais parece ter ocorrido mais efetivamente durante os primeiros dias de exposição em solo contaminado e artificial, respectivamente. Além disso, os oligoquetas foram capazes de depurar/excretar mais de $90 \%$ do total estocado de $\mathrm{Zn}$ e $\mathrm{Cu}$ na etapa bioacumulação, indicando que os animais poderiam ser capazes de se recuperar caso fossem afastados da exposição.
(FBC $>1)$, resultado que pode estar associado ao fato de estes elementos serem considerados essenciais ao funcionamento metabólico desse organismo. Em um futuro próximo, os dados apresentados no presente estudo serão integrados aos de outros bioensaios, visando à estimativa numérica do risco e uma avaliação mais ampla e abrangente do risco ecotoxicológico associado à disposição de sedimentos de dragagem em áreas continentais.

Por fim, os resultados deixam claro que, no caso da disposição de sedimentos de dragagem, a análise química do contaminante no compartimento abiótico, por si só, 
não é capaz de avaliar e/ou prognosticar a ocorrência de efeitos adversos à saúde da biota terrestre. Nesse aspecto, a execução de bioensaios com sedimentos dragados e solos de origens diversas é imperativa, visando à geração de valores orientadores para a concentração de metais pesados capazes de refletir a realidade dos ecossistemas e solos brasileiros.

\section{AGRADECIMENTOS}

Os autores gostariam de agradecer ao Conselho Nacional de Desenvolvimento Científico e Tecnológico (CNPq) pelas bolsas de estudo concedidas a Ricardo Cesar (Doutorado) e Juan Colonese (Iniciação Científica). Os autores também agradecem à Coordenação de
Análises Minerais (COAM) do Centro de Tecnologia Mineral do Ministério da Ciência, Tecnologia e Inovação pelo suporte na análise química de metais e ao geógrafo Ricardo Sierpe pela ajuda na confecção do mapa com os pontos de coleta.

\section{REFERÊNCIAS}

ASTM - American Society for Testing and Materials. 2004. Standard Guide for Conducting Laboratory Soil Toxicity or Bioaccumulation Tests with the Lumbricid Earthworm Eiseniafetida and the enchytraeid potworm Enchytraeus albidus. ASTM 1676-04.

Cesar R.G., Egler S.G., Polivanov H., Castilhos Z.C., Rodrigues A.P., Araújo P.C. 2008. Biodisponibilidade de metilmercúrio, zinco e cobre em distintas frações granulométricas de solo contaminado utilizando oligoquetas da espécie Eiseniaandrei. Anuário do Instituto de Geociências (UFRJ), 31:33-41.

Cesar R.G., Álvaro T.T., Silva M.B., Colonese J., Pereira C., Polivanov H., Egler S.G., Bidone E.D., Castilhos Z.C. 2010a. Biodisponibilidade de contaminantes em solos brasileiros tratados com lodo de esgoto: uma abordagem ecotoxicológica utilizando bioensaios com organismos aquáticos e edáficos. Geochimica Brasiliensis, 24:41-49.

Cesar R.G., Colonese J., Silva M.B., Bertolino L.C., Castilhos Z.C., Egler S.G., Polivanov H., Bidone E.D., Pérez D.V. 2010b. Avaliação da ecotoxicidade de mercúrio em três tipos de solos utilizando ensaios ecotoxicológicos com oligoquetas. Geochimica Brasiliensis, 24:3-12.

Cesar R.G, Silva M., Colonese J., Bidone E.D., Egler S.G., Castilhos Z.C., Polivanov H. 2012. Influence of the properties of tropical soils in the toxicity and bioavailability of heavy metals in sewage sludge-amended lands. Environmental Earth Sciences, 66: 2281-2292.

Cesar R.G., Natal-da-Luz T., Sousa J.P.F., Colonese J., Bidone E.D., Castilhos Z.C., Egler S.G., Polivanov H. 2013a. Disposal of dredged sediments in tropical soils: ecotoxicological effects on earthworms. Environmental Monitoring and Assessment, 186:1487-1497.

Cesar R.G., Mendonça M., Polivanov H., Barroso E.V., Alvaro T.T., Colonese J.P., Egler S.G., Castilhos Z.C. 2013b. Disposição terrestre de sedimento de dragagem: ecotoxicidade aguda, biodisponibilidade de metais e estudo de caso em Belford Roxo - RJ. Revista Geociências (São Paulo), submetido.

Cesar R.G., Polivanov H., Natal-da-Luz T., Bidone E., Castilhos Z., Sousa J.P. 2013c. Disposição continental de sedimentos de dragagem em solos tropicais: uma abordagem ecotoxicológica utilizando colêmbolos e enquitreídeos. In: Congresso Brasileiro de Geologia de Engenharia e Ambiental, 14, Rio de Janeiro, Livro de Abstracts, 56 p.

Chelinho S., Domene X. Camana P., Natal-Da-Luz T., Scheffczyk A., Römbke J., Andrés P., Souza J.P. 2011. Improving ecological risk assessment in the mediterranean area: selection of reference soils and evaluating the influence of soil properties on avoidance and reproduction of two oligochaete species. Environmental Toxicology and Chemistry, 30(5):1050-1058. 
CONAMA - Conselho Nacional do Meio Ambiente. 2012. Resolução 454. Disponível em: http://www.mma.gov.br/port/conama/legiabre. cfm?codlegi=693. Acessado em 14 abr 2014.

Garcia M. 1996. Effects of pesticides on soil fauna: Development of ecotoxicology test methods for tropical regions. In: P.L.G Vlek et al. (eds.). Ecology and Development Series, v. 19, CuvillierVerlag Gottingen, 282 p.

Hinton J. \& Veiga M. 2002. Earthworms as bioindicators of mercury pollution from mining and other industrial activities. Geochemistry, Exploration, Environment, Analysis, 2:269-274.

Ho K.T., Burgess R.M., Pelletier M.C., Serbst J.R., Ryba S.A., Cantwell M.G., Kuhn A., Raczelowski P. 2002. An overview of toxicant identification in sediments and dredged materials. Marine Pollution Bulletin, 44:286-293.

Hortellani M.A., Sarkis J.E., Bonetti J., Bonetti C. 2005. Evaluation of mercury contamination in sediments from Santos - São Vicente Estuarine System, São Paulo State, Brazil. Journal of the Brazilian Chemical Society, 16(6A):1140-1149.

Liu X., Chengxiao H., Zhang S. 2005. Effects on earthworm activity on fertility and heavy metals bioavailability in sewage sludge. Environment International, 31:874-879.

Lukkari T., Astsinki M., Väisänen A., Haimi J. 2005. Toxicity of copper and zinc Assessed with three different earthworms tests. Applied Soil Ecology, 30:133-146.

Machado W., Rodrigues A.P.C., Bidone E.D., Sella S.M., Santelli R.E. 2011. Evaluation of $\mathrm{Cu}$ potential bioavailability changes upon coastal sediment resuspension: an example on how to improve the assessment of sediment dredging environmental risks. Environmental Science and Pollution Research International, 18:1033-1036.

Matzke M., Stolte S., Arning J., UebersU., FilserJ. 2008. Imidazolium based ionic liquids in soils: effects of the side chain length on wheat (Triticumaestivum) and cress (Lepidiumsativum) as affected by different clays and organic matter. Green Chemistry, 10:584-591.

Munns W.R., Berry W.J., Dewitt W.T. 2002. Toxicity testing, risk assessment, and options for dredged material management. Marine Pollution Bulletin, 44:294-302.

NahmaniJ., Hodson M.E., Black S. 2007. A review of studies performed to assess metal uptake by earthworms. Environmental Pollution, 145:402-424.

Natal-da-Luz T., Römbke J., Sousa J.P. 2008.Avoidance tests in site-specific risk assessment-influence of soil properties on the avoidance response of collembola and earthworms. Environmental Toxicology and Chemistry, 27(5):1112-1117.

Natal-da-Luz T., Tidona S., Jesus B., Morais P.V., Sousa J.P. 2009. The use of sewage sludge as soil amendment: The need for an ecotoxicological evaluation. Journal of Soils and Sediments, 9:246-260.

OECD - Organization for Economic Cooperation and Development). 1984. Guideline 208: Terrestrial Plants, Growth Test. OECD Guidelines for testing of chemical. OECD, Paris

Sakuma M. 1998. Probit analysis of preference data. Applied Entomology Zoology, 33:339-347.

Silva T.F., Azevedo D.A., Neto F.R.A. 2007. Distribution of polycyclic aromatic hydrocarbons in surface sediments and waters from Guanabara Bay, Rio de Janeiro, Brazil. Journal of the Brazilian Chemistry Society, 18(3):628-637.

Silveira R.P., Rodrigues A.P.C., Santelli R.E., Cordeiro R.C., Bidone E.D. 2010. Mass balance in the monitoring of pollutants in tidal rivers of the Guanabara Bay, Rio de Janeiro, Brazil. Environmental Monitoring and Assessment, 181:1-9.

Vacha R., Cechmankova J., Skala J., Hoffman J., Cermak P., Sanka M., Vachova T. 2011. Use of dredged sediments on agricultural soils from viewpoint of potentially toxic substances. Plant, Soil and Enviroment, 57(8):388-395. 
Van Gestel C.A.M., Borgman E., Verweij R.A., Ortiz M.D. 2011. The influence of soil properties on the toxicity of molybdenum to three species of soil invertebrates. Ecotoxicology and Environmental Safety, 74:1-9.

Veiga M.M. \& Hinton J.J. 2001. Methylation of mercury-organic compounds by earthworms. In: International Conference on Mercury as a Global Pollutant, 6, Minamata, Japan, Book of Abstracts, 117 p.

WHO - World Health Organization 1990. Environmental Health Criteria (EHC 101). Methylmercury. Geneva. 